\title{
LXXI. On the relation of ozone to hyponitric acid
}

\section{Dr. C.F. Schœnbein}

To cite this article: Dr. C.F. Schœnbein (1846) LXXI. On the relation of ozone to hyponitric acid, Philosophical Magazine Series 3, 28:189, 432-437, DOI: 10.1080/14786444608645454

To link to this article: http://dx.doi.org/10.1080/14786444608645454

曲 Published online: 30 Apr 2009.

Submit your article to this journal 중

Q View related articles $₫$ 
1. The epidermis of plants, so far as experiments have been made, is porous, and permits the passage of gases according to physical laws.

2. The roots, during the existence of chemical changes in plants, absorb such gases from the soil-fluids as will indirectly satisfy the requisitions of the internal atmosphere.

3. The internal gas of plants fluctuates with the forces which operate on the plant; during the active state of the green vegetable, it resembles a mixture of nitrogen 86.75 , oxygen 13.25 per cent., but at night contains more oxygen and a proportion of carbonic acid.

4. The porosity of the entire plant is fully established by its action on artificial atmospheres.

Therefore the physical structure of plants is that of a porous system subject to the laws of diffusion of gases; and endowed with no vitality other than the power of forming cytoblasts and arranging cellules after a definite type.

\section{On the relation of Ozone to Hyponitric Acid.} By Dr. C. F. Schonbein *

THE chemical effects produced by atmospheric air charged with hyponitric acid $\left(\mathrm{NO}_{4}\right)$ are so very like those caused by ozonized air, that some chemists are inclined to consider hyponitric acid as identical with ozone. Both decompose iodide of potassium, transform the yellow prussiate of potash into the red one, decompose sulphuretted hydrogen, colour blue the resin of guaiacum, destroy organic colouring matters, polarize negatively platinum, \&c.

In spite of the similarity of chemical properties exhibited by ozone and hyponitric acid, those substances are in many other respects so entirely different that their being identical cannot be thought of: thus ozone is produced under circumstances in which an essential constituent part of hyponitric acid is absent, namely nitrogen. The analogy existing between the chemical action of the two bodies mentioned appears however so striking, that we can hardly help suspecting some connexion to exist between them, and with the view of ascertaining that connexion I have of late made many experiments, the account of which will form the substance of this paper.

The results obtained from these researches are, in my opinion, such as to speak strongly in favour of my conjecture that there exists a compound composed of $\mathrm{NO}_{2}+\mathrm{HO}_{2}$. It

* Communicated by the Chemical Society; having been read November $3,1845$. 
appears to me probable that besides hydrate of nitric acid a peroxide of nitrogen and hydrogen is formed when water acts upon hyponitric acid. Agreeably to my view, the presence of $\mathrm{NO}_{2}+\mathrm{HO}_{2}$, in the acid mixture, is the cause why the latter decomposes iodide of potassium, \&c.

I think it cannot be denied that aqueous vapour will act upon vaporous hyponitric acid as liquid water does upon the liquid acid. Such being the case, and supposing that in the latter case two compounds of the formulas $\mathrm{NO}_{4}+\mathrm{HO}_{2}$ and $\mathrm{NO}_{2}+\mathrm{HO}_{2}$ are produced, it must then be admitted also that the same compounds are formed when the vapours of hyponitric acid are mixed with moist atmospheric air. Now if the peroxide of nitrogen and hydrogen (the first of thesecompounds) should happen to be a volatile substance, it follows further that in a bottle containing moist air, to which vapour of byponitric acid had been added, an atmosphere must be produced containing some $\mathrm{NO}_{2}+\mathrm{HO}_{2}$, and possessing the property of causing the reactions above mentioned. 'The peroxide of hydrogen contained in $\mathrm{NO}_{2}+\mathrm{HO}_{2}$ would be the oxidizing agent, decomposing e. g. iodide of potassium, \&c.

For various reasons I am inclined to consider ozone as $\mathrm{HO}_{2}$, i. e. a compound isomeric with Thenard's peroxide of hydrogen. Now if this conjecture should be true, and if there should exist a compound of $\mathrm{NO}_{2}+\mathrm{HO}_{2}$, moist atmospheric air being charged with vapour of hyponitric acid would owe its reactions to the presence of ozone. How far such a conjecture is founded upon facts, the experiments $I$ am about to detail will show.

If a piece of carbonate of ammonia, having been strongly ozonized by the means of phosphorus, is suspended in atmospheric air until the latter be so charged with ammoniacal vapours as rapidly to restore the blue colour of reddened litmus paper, that atmosphere continues to enjoy bleaching powers, decomposes iodide of potassium, colours blue the paste of starch containing that salt, transforms the yellow prussiate of potash into the red one, colours the resin of guaiacum blue, discharges the colour of sulphuret of lead; continues, in one word, to possess all the properties belonging to ozone. Hence it follows that ozone is capable of co-existing with the vapours of carbonate of ammonia without suffering decomposition; and I have ascertained that pure ammonia also does not perceptibly destroy ozone. Now if there exists $\mathrm{NO}_{2}+\mathrm{HO}_{2}$, we may presume from its constitution that it will likewise be able to coexist with the vapours of the carbonate of ammonia, $\mathrm{NO}_{2}$ being of itself inactive towards ammonia.

Hyponitric acid, or red fuming nitric acid, was gradually mixed up with so much water as to obtain a colourless liquid. 
The bottom of a spacious bottle was covered with this mixture, and then a large piece of carbonate of ammonia suspended within the vessel. After the atmosphere, standing over the acid liquid, had assumed the power of colouring rapidly blue a strip of reddened litmus paper, it continued to possess the following properties:-

1. Strips of paper charged with paste of starch containing some iodide of potassium were coloured blue.

2. Strips of paper drenched with an alcoholic solution of guaiacum assumed a blue colour.

3. Strips of paper coloured blue by a solution of indigo turned white.

4. Strips of paper to which sulphuret of lead had been attached, by means of nitrate of lead and sulphuretted hydrogen, gradually turned white.

5. Strips of paper charged with a solution of the common prussiate of potash became deeply yellow.

6. Crystals of the yellow prussiate, after having been suspended for twenty-four hours within this atmosphere, were covered with a crust of the red sesqui-ferrocyanuret of potassium.

From the facts just stated, it appears that the atmosphere in question acts exactly in the same way as ozonized air does, and from the circumstances under which those reactions took place, it follows that the latter could not proceed from free hyponitric or nitrous acid, these acids not being able to coexist in a state of isolation with the vapours of carbonate of ammonia. We must therefore conclude from these facts, that there was a principle present, in the atmosphere mentioned, which acted after the manner of ozone, and conducted itself, in spite of the presence of ammoniacal vapour, as a highly oxidizing agent.

But if neither free hyponitric nor nitrous acid were the cause of the reactions mentioned, nor nitrite of ammonia, what then is the substance to which the oxidizing powers are to be ascribed? I can answer that question only by supposing that the peroxide of nitrogen and hydrogen is that agent. Before passing to another subject, I take the liberty to mention a circumstance which seems to bear upon the matter in question, and merit some attention. On breathing strongly ozonized air three or four times, a disagreeable and strangling sensation will be experienced near the throat and in the chest. This sensation is very similar to that caused by inhaling air which has stood for some time over a mixture of hyponitric acid and water, and this is the case even if the air happens to be charged with ammoniacal vapours. We observe also in such an atmosphere a peculiar and disagreeable odour, 
which is similar to that of common aquafortis, and slightly analogous to the smell of chlorine. It is likely that the odour mentioned belongs to the vapour of our supposed peroxide of nitrogen and hydrogen, and that it is that compound which, if inhaled, causes the sensation before mentioned. With regard to the subject under discussion, it seems to me that the way in which the mixture, formed from hyponitric acid and water, acts upon a solution of the yellow prussiate of potash, offers peculiar interest.

My experiments having demonstrated that the salt just mentioned (be it solid or dissolved in water) is readily transformed into the red cyanuret by ozone, and considering the acid mixture before alluded to as an aqueous solution of nitric acid and peroxide of nitrogen and hydrogen, what must happen if that mixture be put together with a solution of the yellow prussiate of potash? Supposing 1 equiv. of the said peroxide and 1 equiv. of nitric acid in the acid mixture to act upon 2 equiv. of the yellow cyanuret, we must obtain from such a reaction 1 equiv. of nitrate of potash, 1 equiv. of the red sesquiferrocyanuret of potassium, 1 equiv. of deutoxide of nitrogen, and 2 equiv. of water, for

$$
\begin{gathered}
\left(\mathrm{NO}_{4}+\mathrm{HO}_{2}\right)+\left(\mathrm{NO}_{2}+\mathrm{HO}_{2}\right)+2(2 \mathrm{P} \mathrm{Cy}+\mathrm{Fe} \mathrm{Cy})=\mathrm{PO} \mathrm{NO}_{5} \\
+\left(3 \mathrm{P} \mathrm{Cy}+\mathrm{Fe}_{2} \mathrm{Cy}_{3}\right)+\mathrm{NO}_{2}+2 \mathrm{HO} .
\end{gathered}
$$

If a glass tube, open at one end, be half-filled with our acid mixture and half with a dilute solution of the yellow prussiate, on mixing the liquids together a lively disengagement of gas takes place; and if the open end of the tube be put into a vessel holding water, a colourless gas will fill the upper part of the tube. On alding oxygen or atmospheric air to the gas disengaged under the circumstances mentioned, the latter will turn brownish red and exhibit all the properties of deutoxide of nitrogen. As soon as the acid mixture comes in contact with the nearly colourless solution of the common prussiate of potash, the latter turns deeply yellow, and it is very easy to ascertain that the coloured fluid contains nitrate of potash, sesqui-ferrocyanuret of potassium, and no trace of the yellow prussiate, prorided a sufficient quantity of the acid mixture hall been employed. The reactions indicated are therefore such as they ought to be, if, according to our supposition, the acid mixture contains nitric acid and peroxicle of nitrogen and hydrogen. I need hardly say that the disengagement of deutoxide of nitrogen and the transformation of the yellow cyanuret into the red one, which take place under the circumstances mentioned, cannot originate in the nitric acid contained in the acid mixture, for it is well known that dilute pure nitric 


\section{$436 \mathrm{Dr}$. Schœnbein on the relation of Ozone to Hyponitric Acid.}

acid does not give rise to the reactions described. The cause of those effects must therefore be sought in another substance, and both hyponitric and nitrous acid not being able to coexist with free water, we are not allowed to consider either the one or the other of those acids as that cause. As I have already remarked, the reactions in question can, according to my opinion, only be accounted for in a satisfactory manner by admitting the presence of $\mathrm{NO}_{2}+\mathrm{HO}_{2}$ in the acid mixture so often mentioned. My experiments have further shown that iodide of potassium, be it solid or dissolved in water, is readily decomposed by ozone, iodine being eliminated. In putting our acid mixture to a solution of the salt mentioned, deutoxide of nitrogen is abundantly disengaged, iodine precipitated, and nitrate of potash formed. As pure nitric acid containing as much water as the said acid mixture, does not act upon the solution of iodide of potassium, it cannot be the nitric acid of our mixture that causes those phænomena, nor can they, from reasons already stated, proceed from hyponitric or nitrous acids.

If we admit that there is, besides nitric acid, some $\mathrm{NO}_{2}$ $+\mathrm{HO}_{2}$ present in the acid mixture, I think we may easily account for those reactions. $\mathrm{HO}_{2}$ oxidizes the potassium of the iodide, nitric acid unites with the base thus formed, and $\mathrm{NO}_{2}$ is set free.

$$
\begin{aligned}
& \left(\mathrm{NO}_{4}+\mathrm{HO}_{2}\right)+\left(\mathrm{NO}_{2}+\mathrm{HO}_{2}\right)+\mathrm{PI}=\mathrm{PO} \mathrm{NO}_{5}\left(\mathrm{PO}_{2} \mathrm{NO}_{4}\right) \\
& \quad+\mathrm{I}+\mathrm{NO}_{2}+\mathrm{HO} .
\end{aligned}
$$

The facts I am about to state are most likely also connected with the subject under discussion.

Largely diluted pure nitric acid, not colouring in the least paste of starch containing chemically pure iodide of potassium, when put for a short time in contact with a number of metals, as zinc, iron, lead, copper, mercury, silver, \&c., acquires the property-1. 'To colour deeply blue the paste mentioned. 2. To transform the yellow cyanuret into the red one. 3. To colour blue the resin of guaiacum. 4. To decompose sulphuretted hydrogen, \&c.

Tin is an exception to the rule, for however long dilute nitric acid may have been in contact with that metal, it does not cause the reactions indicated. On the contrary, an acid having the properties mentioned, loses them when mixed in proper quantities with dilute nitric acid which has been in contact with tin. The latter acid has also the power of discharging the colour of paste of starch rendered blue by iodine. From the facts stated, it seems to follow, that when dilute nitric acid is acted upon by oxidable metals, the same oxidizing 
Prof. Graham on the Composition of Fire-Damp. 437

agent is produced that forms on mixing hyponitric acid with water; and it appears also that tin engenders with dilute nitric acid a deoxidizing matter, i.e. a nitrate of protoxide of tin.

LXXII. On the Composition of the Fire-Damp of the Nerocastle Coal Mines. By Thomas Graham, Esq., F.R.S.*

SOME years ago I examined the gas of these mines, with $\$$ the same result as Dr. Henry, Davy and Dr. Turner had previously obtained, namely, that it contains no other combustible ingredient than light carburetted hydrogen. But the analysis of the gas of the coal mines in Germany, subsèquently published, showing the presence of other gases, particularly of olefiant gas, has rendered a new examination of the gas of the English mines desirable. The gases were,-1, from a seam named the Five-Quarter seam, in the Gateshead colliery, where the gas is collected as it issues, and used for lighting the mine; 2, the gas of Hebburn colliery, which issues from a bore let down into the Bensham seam-a seam of coal which is highly charged with gas, and has been the cause of many accidents; and 3, gas from Killingworth colliery, in the neighbourhood of Jarrow, where the last great explosion occurred. This last gas issues from a fissure in a stratum of sandstone, and has been kept uninterruptedly burning, as the means of lighting the horse-road in the mine, for upwards of ten years, without any sensible diminution in its quantity. The gases were collected personally by my friend $\mathrm{Mr}$. J. Hutchinson, with every requisite precaution to ensure their purity, and prevent admixture of atmospheric air.

The usual eudiometrical process of firing the gases with oxygen was sufficient to prove that they all consisted of light carburetted hydrogen, with the exception of a few per cent. The results were as follows:-

Gateshead Gas.-Specific gravity 0.5802.

Carburetted hydrogen . • . . $94 \cdot 2$

Nitrogen . . . . . . . . 4.5

Oxygen . $\cdot \cdot \cdot \cdot \cdot \cdot \cdot \frac{1 \cdot 3}{100 \cdot 0}$

The density of such a mixture is, by calculation, 0.5813 .

Killingworth Gas.-Specific gravity 0.6306.

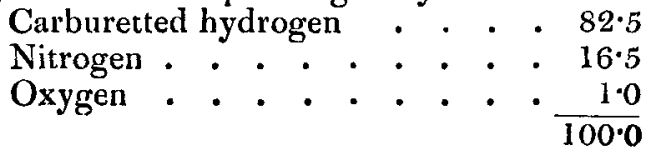

* Communicated by the Chemical Society; having been read November 3, 1845. 